\title{
Efficacy of endobronchial ultrasound-guided transbronchial needle aspiration repeat-biopsy
}

\author{
Chun-Li Tang", Di-Fei Chen", Chang-Hao Zhong, Yu Chen, Xiao-Bo Chen, Rong-Mei Geng, Shi-Yue Li \\ State Key Laboratory of Respiratory Disease, The First Affiliated Hospital of Guangzhou Medical University, National Clinical Research Center for \\ Respiratory, Guangzhou Institute of Respiratory Disease, Guangzhou, China \\ \#These authors contributed equally to this work. \\ Correspondence to: Shi-Yue Li. The First Affiliated Hospital of Guangzhou Medical University, National Clinical Research Center for Respiratory, \\ Guangzhou Institute of Respiratory Disease, Guangzhou 510120, China. Email: lishiyue@188.com.
}

Submitted Jul 30, 2021. Accepted for publication Oct 19, 2021.

doi: 10.21037/jtd-21-1251

View this article at: https://dx.doi.org/10.21037/jtd-21-1251

Endobronchial ultrasound-guided transbronchial needle aspiration (EBUS-TBNA) has been considered as a novel and accurate method for precise sampling of mediastinal lymph nodes and peribronchial lesions with a diagnosis yield of about $93-97 \%(1,2)$. So far, some studies have reported that EBUS-TBNA may not precisely diagnose mediastinal lymph nodes and peribronchial lesions for some situations. Therefore, to avoid a repeat sampling procedure, a better method of biopsy should be applied. However, given the high sensitivity and specificity of EBUS-TBNA method, repeat EBUS-TBNA (repeat-biopsy) may yield satisfactory results (3). Here, we retrospectively reviewed data of patients who underwent multiple EBUS-TBNA at The First Affiliated Hospital of Guangzhou Medical University from January 2012 to June 2020. The study was approved by the Institutional Ethic Committee of the First Affiliated Hospital of Guangzhou Medical University (\#2020131).

Among 4,911 patients who received EBUS-TBNA, 140 patients $(2.85 \%)$ underwent multiple procedures. Specifically, 131 patients received two procedures, eight patients received three procedures, and one patient received four procedures. Except 44 patients show received multiple procedures with the aim of reviewing disease or genetic testing. Ninety-six patients received repeat biopsy due to unexpected or non-diagnostic results in the first biopsy. These patients were further divided into 3 groups based on reasons for the repeat-biopsy: (I) 55 patients showed atypical results, i.e., abnormal cytopathology results with no diagnostic significance; (II) 24 patients had negative results; (III) 17 patients underwent repeat biopsy due to poor quality of samples. All patients were followed up for a long period to confirm the diagnosis. The final diagnosis which was based on pathological analysis was considered as the correct diagnosis. The characteristics of patients followed up are shown in Table 1.

This report focuses on two main questions: (I) does repeat-biopsy improve the rate of correct diagnosis? (II) What are the factors influencing the diagnostic accurate of repeat-biopsy?

Overall, the correct diagnosis rate of repeat-biopsy was $67.7 \%$ (65/96), but there were significant differences in correct rates between groups. Patients who showed negative results in the first EBUS-TBNA procedure had a lower correct rate [45.8\% (11/24)] in repeat-biopsy compared with those with atypical sample $[72.7 \%(40 / 55)]$ and those who had samples with poor quality [82.4\% $(14 / 17)](\mathrm{P}<0.001)$. It was found that site of biopsy may greatly affect the correct rate. Consequently, repeat-biopsy for peribronchial lesions achieved a correct rate of $93.8 \%(15 / 16)$ whereas that for lymph nodes had a correct rate of $62.5 \%(50 / 80)$.

For the 24 patients who had negative results, their CT scans were examined to analyze the gross features of the biopsied lymph nodes. Notably, small lymph nodes (short axis $<10 \mathrm{~mm}$ ) were punctured in 3 patients. The main characteristics of the biopsied nodes were inhomogeneous density [37.5\% (9/24)] and irregular margins [50\% (12/24)].

In the subsequent sections, we discuss a patient who received EBUS-TBNA 4 times. The patient was a 51-yearold man who was admitted to the hospital due to a mass in the left lung. PET-CT scans confirmed the presence 
Table 1 Baseline and correct rate of included patients

\begin{tabular}{|c|c|c|}
\hline Characteristic & Result & $P$ value \\
\hline Included patients (n) & 96 & \\
\hline \multicolumn{3}{|l|}{ The location of the biopsy (n) } \\
\hline Lymph nodes & 80 & \\
\hline Peribronchial lesion & 16 & \\
\hline \multicolumn{3}{|l|}{ Reasons of re-biopsy (n) } \\
\hline Negative biopsy & 24 & \\
\hline Atypical biopsy & 55 & \\
\hline Poor quality sample & 17 & \\
\hline \multicolumn{3}{|l|}{ Operating factors in re-biopsy (n) } \\
\hline Change/add biopsy points & 69 & \\
\hline Replacement of operator & 62 & \\
\hline \multicolumn{3}{|l|}{ Final diagnosis $(n)$} \\
\hline Malignant disease & 51 & \\
\hline Squamous cell carcinoma & 16 & \\
\hline Adenocarcinoma & 24 & \\
\hline Lymphoma & 6 & \\
\hline Other & 5 & \\
\hline Benign disease & 45 & \\
\hline Sarcoidosis & 3 & \\
\hline Pulmonary infect & 6 & \\
\hline Tuberculosis & 17 & \\
\hline Other & 19 & \\
\hline \multicolumn{3}{|l|}{ Correct rate of re-biopsy (\%) } \\
\hline Overall & $67.7(65 / 96)$ & \\
\hline Negative biopsy & $45.8(11 / 24)$ & $<0.001$ \\
\hline Atypical biopsy & $72.7(40 / 55)$ & \\
\hline Poor quality sample & $82.4(14 / 17)$ & \\
\hline Malignant disease & $68.6(35 / 51)$ & $>0.05$ \\
\hline Benign disease & $66.6(30 / 45)$ & \\
\hline Lymph nodes & $62.5(50 / 80)$ & $<0.001$ \\
\hline Peribronchial lesion & $93.8(15 / 16)$ & \\
\hline Change/add biopsy points & $63.7(44 / 69)$ & $>0.05$ \\
\hline Replacement of operator & $66.1(41 / 62)$ & \\
\hline
\end{tabular}

of a central lung neoplasm in the left upper lung with multiple mediastinal lymph node metastases. The initial EBUS-TBNA performed in $4 \mathrm{R}$ and $7 \#$ lymph nodes showed negative results. To prevent false negatives, a second lymph node biopsy was carried out. Similar to the first biopsy, the result was negative on repeat-biopsy, and even mediastinoscopic biopsy found no tumor. The patient received conservative therapy for two weeks but his symptoms did not improve. The patient was advised to undergo surgery to confirm the diagnosis, but he refused. Therefore, EBUS-TBNA was repeated twice and a small group of heteromorphic cells was found, but no tumor was confirmed. Finally, the patient was diagnosed with a special pathogen infection. After long-term follow-up, the result showed that there was no significant progress in lung mass. This case demonstrates poor efficacy of EBUS-TBNA repeat-biopsy for an initially negative result.

Although EBUS-TBNA has extremely high sensitivity and specificity, it has been reported to obtain negative results across different diseases. Therefore, it is important to develop a standard protocol for handling cases where patients show negative EBUS-TBNA results. Overall, compared with the unstable diagnostic yield of conventional-TBNA (which ranges from $20 \%$ to $80 \%$ ) (4), repeat-biopsy achieves a correct diagnosis rate of $66.7 \%$. However, the application of EBUS-TBNA should be decided based on the actual patient situation. The present case shows that repeat EBUS-TBNA can lead to a successful diagnosis for patients with atypical pathological results or poor-quality samples. For negative results, repeatbiopsy had a low rate of correct diagnosis, hence a more effective biopsy modality should be considered. Rapid onsite evaluation (ROSE) is a simple procedure that cam provide an immediate and accurate assessment of benign and malignant samples. Moreover, the procedure can avoid additional sampling (5). However, there is no consensus on the necessity of ROSE in combination with EBUSTBNA. Recently, EBUS-guided intranodal forceps (EBUSINF) biopsy has been shown to provide larger histologic tissue samples. Using samples from EBUS-INF to perform genetic analysis may avoid repeat-biopsy for cases where the tissue sample is insufficient. Meanwhile, for suspected false-negative EBUS-TBNA results, EBUS-INF can be an alternative method for confirmation purposes (6). 
Other factors that may also influence the efficacy of EBUS-TBNA include CT image characteristics, such as inhomogeneous density and irregular margins. A recent report indicated that PET/CT can increase the diagnostic efficacy of EBUS-TBNA (7), and choosing a PET-positive lymph node may improve the correct rate of repeat-biopsy.

\section{Acknowledgments}

Funding: None.

\section{Footnote}

Provenance and Peer Review: This article was a standard submission to the journal. The article has undergone external peer review.

Peer Review File: Available at https://dx.doi.org/10.21037/ jtd-21-1251

Conflicts of Interest: All authors have completed the ICMJE uniform disclosure form (available at https://dx.doi. org/10.21037/jtd-21-1251). The authors have no conflicts of interest to declare.

Etbical Statement: The authors are accountable for all aspects of the work in ensuring that questions related to the accuracy or integrity of any part of the work are appropriately investigated and resolved.

Open Access Statement: This is an Open Access article distributed in accordance with the Creative Commons Attribution-NonCommercial-NoDerivs 4.0 International
License (CC BY-NC-ND 4.0), which permits the noncommercial replication and distribution of the article with the strict proviso that no changes or edits are made and the original work is properly cited (including links to both the formal publication through the relevant DOI and the license). See: https://creativecommons.org/licenses/by-nc-nd/4.0/.

\section{References}

1. Fielding D, Kurimoto N. Endobronchial Ultrasound-Guided Transbronchial Needle Aspiration for Diagnosis and Staging of Lung Cancer. Clin Chest Med 2018;39:111-23.

2. Conte SC, Spagnol G, Biolo M, et al. A retrospective study of endobronchial ultrasound transbronchial needle aspiration versus conventional transbronchial needle aspiration in diagnosis/staging of hilar/mediastinal lymph node in lung cancer: Which role in clinical practice? Monaldi Arch Chest Dis 2019;89.

3. Liam CK, Lee P, Yu CJ, et al. The diagnosis of lung cancer in the era of interventional pulmonology. Int $\mathrm{J}$ Tuberc Lung Dis 2021;25:6-15.

4. Küpeli E. Conventional transbronchial needle aspiration in community practice. J Thorac Dis 2015;7:S256-65.

5. Li C, Xie W, Cao J, et al. Detailed procedure and clinical application overview of rapid on-site evaluation in diagnostic interventional pulmonology. J Res Med Sci 2020;25:35.

6. McLaughlin J, Liu C, Collins DT, et al. The Safety and Feasibility of Endobronchial Ultrasound Bronchoscopyguided Intranodal Forceps Biopsies (EBUS-INF). Clinical Pulmonary Medicine 2020;27:113-7.

7. Guarize J, Casiraghi M, Donghi S, et al. EBUS-TBNA in PET-positive lymphadenopathies in treated cancer patients. ERJ Open Res 2017;3:00009-2017.
Cite this article as: Tang CL, Chen DF, Zhong CH, Chen Y, Chen XB, Geng RM, Li SY. Efficacy of endobronchial ultrasound-guided transbronchial needle aspiration repeatbiopsy. J Thorac Dis 2021;13(10):6108-6110. doi: 10.21037/jtd$21-1251$ 